Jurnal Spektrum Komunikasi Vol 6 No. 2 Desember, 2018

\title{
ANALISIS WACANA FEATURES “38 TAHUN MENJAGA KERTAS SEMEN TITIPAN PRAMOEDYA” DI CNNINDONESIA.COM
}

\author{
DISCOURSE ANALYSIS OF FEATURES "38 YEARS OF \\ SAFEGUARDING PRAMOEDYA CEMENT PAPER" ON \\ CNNINDONESIA.COM
}

\author{
Hilda Meilisa Rinanda \\ Wartawan beritajatim.com \\ Email : hildameilisaa@gmail.com
}

\begin{abstract}
Pramoedya Ananta Toer's works are timeless. After his death on 30 April 2006, his book is still in demand on the market, his name is still fragrant on earth even though his body has been buried. To commemorate his decade of departure, CNNIndonesia.com summarizes all of Pram's issues through the focus channel. The stories of Pram poured on some news. One of them is written in the news entitled "38 Tahun Menjaga Kertas Semen Titipan Pramoedya" by Rizky Sekar Afrisia, journalist of CNNIndonesia.com. This story tells about Hwie, Pram's comrade on Buru Island who keeping the original script of Pram's books on cement paper. In contrast to other news, the news writer wrote it with Hwie's point of view as the "me" figure. Not only that, in the news also flavored atmosphere setting, complex descriptions, and a fitting groove to make the reader as if in a braided story. The paradigm used in this research is the view of constructivism. Researchers use this paradigm because the constructivist mindset emphasizes meaningful politics and the process of how one makes a picture of reality. While this research uses qualitative approach with scalpel technique of discourse analysis of Teun A. Van. Dijk. In this case there are three elements to be analyzed, text, social cognition and social context. Researchers prefer Van Dijk discourse analysis because in addition to researching the text, researchers want to know the meaning and reason until the production process of the news. From the brief explanation, it can be concluded that in the text of the news, many meanings to be emphasized by journalists. This can be found from the number of paragraph writing by paragraph which is quite detailed and descriptive. Not only that, this news also inserted the atmosphere in the Orde Baru era where freedom is still very limited, especially to political prisoners who are imprisoned without trial, as well as how cruel and strict treatment on the island exile, Buru.
\end{abstract}

Keywords: Features, Van Dijk Discourse Analysis, News Text Discourse, Pramoedya Ananta Toer, CNNIndonesia.com

\footnotetext{
ABSTRAK

Karya-karya Pramoedya Ananta Toer tak lekang oleh waktu. Usai sepeninggalnya pada 30 April 2006, bukunya masih laris di pasaran, namanya masih harum di bumi meski jasadnya telah dikebumikan. Untuk peringati satu dekade kepergiannya, CNNIndonesia.com merangkum semua perihal Pram lewat kanal fokus. Kisah-kisah

ISSN 2338 - 0861 (cetak); e-ISSN 2621 - 8712 (online)

website : http://spektrum.stikosa-aws.ac.id
} 
Pram dituangkan pada beberapa berita. Salah satunya yang ditulis dalam berita berjudul "38 Tahun Menjaga Kertas Semen Titipan Pramoedya" karya Rizky Sekar Afrisia, wartawan CNNIndonesia.com. Berita ini bercerita tentang Hwie, kawan Pram di Pulau Buru yang menjaga naskah asli buku-buku Pram yang tertuang di kertas semen. Berbeda dengan berita lainnya, penulis berita tersebut menulisnya dengan sudut pandang Hwie yang menjadi sosok "aku". Tak hanya itu, dalam berita juga dibumbui latar suasana, deskripsi yang kompleks, dan alur yang pas hingga membuat pembaca seolah berada dalam jalinan cerita.Paradigma yang digunakan dalam penelitian ini adalah pandangan konstruktivisme. Peneliti menggunakan paradigma ini karena pola pikir konstruktivis menekankan pada politik pemaknaan dan proses bagaimana seseorang membuat gambaran tentang realitas. Sedangkan penelitian ini menggunakan pendekatan kualitatif dengan pisau bedah teknik analisis wacana milik Teun A. Van. Dijk. Dalam hal ini terdapat tiga unsur yang akan dianalisis, yakni teks, kognisi sosial dan konteks sosial. Peneliti lebih memilih analisis wacana Van Dijk lantaran selain ingin meneliti teksnya, peneliti ingin mengetahui makna serta alasan hingga proses produksi berita tersebut.Dari penjelasan singkat, dapat diambil kesimpulan bahwa dalam karya berita "38 Tahun Menjaga Kertas Semen Titipan Pramoedya”, banyak makna yang ingin ditekankan oleh wartawan. Hal ini dapat ditemui dari penulisan paragraf demi paragraf yang cukup detil dan deskriptif. Misalnya saja pada elemen leksikon dengan pemilihan kosakata yang cukup merepresentasikan suasana kala itu. Tak hanya itu, berita ini juga menyisipkan latar suasana pada masa Orde Baru, pada masa itu kebebasan masih sangat dibatasi, terlebih kepada para tahanan politik yang dipenjara tanpa diadili, juga bagaimana kejam dan ketatnya perlakuan di pulau pengasingan, Buru.

Kata-kata Kunci: Features, Analisis Wacana Van Dijk, Wacana Teks Berita, Pramoedya Ananta Toer, CNNIndonesia.com

\section{PENDAHULUAN}

Dunia telah memasuki era baru yang biasa disebut dengan era digital. Hal ini ditandai dengan munculnya banyak teknologi yang semakin canggih, juga dengan kecepatan akses internet yang semakin cepat. Kini, kedua hal tersebut telah menjadi kebutuhan manusia guna yang membantu aktivitas sehari-hari.

Namun, era digital juga mengakibatkan banjirnya akses informasi yang masuk ke masyarakat. Bahkan sekarang, untuk membaca berita saja, masyarakat perlu memverifikasi apa yang telah ia baca. Karena, perkembangan era digital yang semakin pesat ini membuat siapa saja, kapan saja, dan dimana saja bisa membagikan informasi apapun yang ia punya melalui blog pribadi juga media sosial miliknya.

Menilik dari beberapa hal di atas, tak salah jika menyebut ilmu jurnalistik selalu berkembang. Begitu pula dengan jurnalisme yang kini telah memasuki babak baru. Asep Syamsul M. Romli dalam bukunya yang bertajuk Jurnalistik Online memaparkan dunia jurnalistik memasuki generasi ketiganya setelah munculnya 'jurnalistik online'. Mengawali sebelumnya generasi pertama yakni jurnalistik cetak (print journalism) dengan adanya surat kabar, tabloid dan majalah. Kemudian disusul dengan jurnalistik elektronik (broadcast journalism) melalui televisi dan radio. Bahkan dulu dikenal istilah "The Big Five of Mass

ISSN 2338 - 0861 (cetak); e-ISSN 2621 - 8712 (online)

website : http://spektrum.stikosa-aws.ac.id 
Media" (Lima Besar Media Massa) yang ditujukan kepada surat kabar (koran), majalah, radio, televisi, dan film.

Melihat berbagai kemudahan yang disuguhkan, kini telah melahirkan banyak portal media daring baru yang siap bersaing di masyarakat. Dewasa ini, dengan adanya perkembangan teknologi yang kian pesat, masyarakat juga menginginkan informasi yang serba cepat. Bukan hanya dalam hitungan hari seperti penerbitan koran pada umumnya, namun media online menyajikan informasi yang real time, hanya hitungan detik dari kejadian yang sedang berlangsung.

Namun, media daring tidak memiliki keunggulan seperti apa yang dimiliki media konvensional, yakni menyajikan berita lebih panjang beserta data yang lengkap, atau biasa dikenal dengan indepth.

Karakter masyarakat Indonesia memang beragam, ada yang lebih menyukai berita yang singkat, terlebih pada pemberitaan lempang (straight news). Namun, ada pula masyarakat yang lebih menyukai pemberitaan panjang dengan data yang berlimpah. Penulisan seperti ini biasa disebut dengan aliran jurnalisme sastrawi. Dalam buku berjudul Jurnalisme Sastrawi : Antologi Liputan Memikat dan Mendalam, Andreas Harsono secara tersirat menjelaskan, jika jurnalisme sastrawi berbeda dengan jurnalisme sastra. Jurnalisme sastra adalah tulisan jurnalis yang membahas tentang sastra. Sedangkan jurnalisme sastrawi merupakan tulisan jurnalis yang di dalamnya menggunakan penulisan bermodel sastra.

Misalnya saja pada features berjudul "38 Tahun Menjaga Kertas Semen Titipan Pramoedya" karya Rizky Sekar Afrisia di CNNIndonesia.com.
Berita ini muncul di kanal fokus, rubrik hiburan yang bertajuk "Satu Dekade Kepergian Pram" pada 30 April 2016. Pemilihan diksi yang cukup beragam, juga penulisan tokoh yang menggunakan sudut pandang aku atau orang pertama, membuat karya tersebut mampu membius pembaca seakan sedang mendalami suatu karya sastra. Tak hanya itu, pembaca pun ikut larut dalam kisah yang disuguhkan melalui alur cerita tersebut. Sama halnya seperti autobiografi suatu tokoh, laporan jurnalistik ini menggunakan bahasa tutur, seperti sedang menceritakan suatu kisah. Membuat pembaca masuk ke dalam jalinan cerita dan juga merasakan bagaimana menjadi tokoh aku.

Peneliti sengaja memilih features ini lantaran berita ini bisa membuat pembaca menjadi 'kenyang'. Kenyang dalam arti tak hanya mendapat informasi terkait kisah Pramoedya dan kawannya di Pulau Buru. Namun, latar sejarah yang dituliskan di sini membuat pembaca sedikit banyak akan mengetahui sejarah Indonesia di masa pergantian ke Orde Baru yang selama ini masih buram.

Berita feature merupakan salah satu bentuk penulisan non fiksi dengan karakter human interest yang kuat. Bedanya dengan hard news, feature juga merupakan sebuah karya jurnalistik namun tidak selalu harus mengikuti rumus klasik $5 \mathrm{~W}+1 \mathrm{H}$. Feature adalah jenis tulisan yang bersifat menghibur, isinya kadang berupa sesuatu yang remeh dan luput dari liputan wartawan hard news, namun tidak terlalu terikat dengan tenggat waktu. Feature bisa ditulis kapan saja dan dipublikasi kapan saja. Karenanya, berita bergenre feature memiliki ciri awet. Penulisannya juga lebih santai, tidak dituntut tenggat

ISSN 2338 - 0861 (cetak); e-ISSN 2621 - 8712 (online)

website : http://spektrum.stikosa-aws.ac.id 
waktu, dan bisa bicara data apa saja lantaran tidak dipatok $5 \mathrm{~W}+1 \mathrm{H}$.

Sebuah feature hendaknya ditulis dengan gaya bertutur dan deskriptif sehingga susunan kata dan kalimatnya mampu menggambarkan atau melukiskan suatu profil atau peristiwa tertentu. Oleh karena itu, feature sesungguhnya sebuah "cerita", tapi bukan cerita mengenai fiksi melainkan mengenai fakta. Teks berita berjudul "38 Tahun Menjaga Kertas Semen Titipan Pramoedya" masuk jenis berita feature, lantaran menggunakan diksi yang lebih banyak gaya bertutur dan deskriptif. Dalam isi berita tersebut menceritakan sebuah peristiwa yang telah terjadi beberapa puluh tahun yang lalu. Sebab hal itu, berita ini tidak dimasukkan dalam kategori hard news lantaran kejadiannya bukan baru-baru ini.

Dalam menganalisis wacana yang digunakan pada penulisan berita berjudul "38 Tahun Menjaga Kertas Semen Titipan Pramoedya" di CNNIndonesia.com, peneliti menggunakan analisis wacana (discourse analysis). Analisis wacana dimaksudkan sebagai suatu analisis untuk membongkar maksud-maksud dan makna-makna tertentu (Eriyanto, 2001:5). Analisis wacana yang digunakan adalah milik Teun A. van Dijk. Studi analisis wacana biasanya digunakan dalam menganalisis teks berita, puisi, juga bisa suatu karangan seperti cerpen. Analisis wacana adalah metode yang digunakan untuk mengetahui bagaimana sebuah pesan disampaikan lewat kata, frasa, kalimat, dan metafora. Dengan melihat bagaimana struktur dari sebuah bahasa yang digunakan, analisis wacana dapat melihat makna yang tersembunyi dari sebuah teks.

\section{METODOLOGI}

Untuk penerapannya, peneliti lebih memilih menggunakan metode analisis wacana karena dinilai lebih mampu untuk mendapatkan hasil maksimal yang diharapkan ketika menggunakan metode ini. Di dalam sebuah teks berita terdapat teks yang bergabung menjadi satu rangkaian kata-kata yang mempunyai maksud dan makna tersendiri. Menurut Van Dijk, penelitian atas wacana tidak cukup sebatas teks semata, lantaran teks hanya hasil dari suatu proses atau praktik produksi yang juga harus diamati. Disini harus dilihat juga bagaimana sebuah teks diproduksi, sehingga kita memperoleh suatu pengetahuan kenapa teks bisa seperti itu (Eriyanto, 2001: 221).

\section{HASIL DAN PEMBAHASAN HASIL KODING ANALISIS TEKS Struktur Makro}

Elemen: Topik atau Tema

Temuan :Kisah dari sudut pandang Oei Hiem Hwie, teman Pramoedya Ananta Toer di Pulau Buru yang dititipi kertas semen berisi tulisantulisan Pram sebelum dijadikan buku.

\section{Superstruktur}

Elemen: Skema/Kerangka

Temuan :

- Berita ini berjudul "38 Tahun Menjaga Kertas Semen Titipan Pramoedya"

- Lead berisi sebuah kutipan berupa pertanyaan dari teman seperjuangan kepada sosok Aku yang diperankan Hwie. Hwie adalah kawan Pramoedya Ananta Toer, sesama tahanan di Pulau Buru yang akan bebas.

- Isi: Kisah sosok Aku di Pulau Buru yang menyediakan kertas semen untuk dijadikan

ISSN 2338 - 0861 (cetak); e-ISSN 2621 - 8712 (online)

website : http://spektrum.stikosa-aws.ac.id 
Pramoedya sebagai media menulis gagasannya sebelum dijadikan sebuah buku.

\section{Struktur Mikro (Semantik)}

Elemen: Latar

Temuan:

- Latar Tempat: Pulau Buru, Kota Malang, Kota Batu, Surabaya, Perpustakaan Hwie di Surabaya.

- Latar Waktu: November 1978, tahun 1970, setelah peristiwa 1965.

- Latar Suasana: Suasana ramai di atas kapal saat perjalaan ke Pulau Buru.

Elemen: Detail

Temuan:

- $\quad$ Detil terdapat pada paragraf 6 yang menggambarkan lokasi dimana Hwie dipenjara.

- Detil selanjutnya berada di paragraf yang menggambarkan lokasi disimpannya naskah Pram.

- Misalnya di kalimat berikut yang menjelaskan secara rinci."Kembali soal cor semen, balok itu juga berfungsi merekatkan kertas naskah Pak Pram setelah dilem sagu. Sekarang di tanganku, cor itu kembali menyamarkan naskah Pak Pram. Naskah dan cor yang beratnya minta ampun itu kubungkus dengan bajubaju kotorku."

Elemen: Maksud

Temuan:

- Dari paragraf tiga, elemen maksud terdapat pada kata alias yang menerangkan secara jelas maksud dari julukan "Mako" yakni Markas Komando. Kalimatnya seperti ini "Pak Pram, begitu aku

biasa memanggilnya,

menanyakan soalan itu saat aku menemuinya di sebuah komplek tahanan yang kami juluki "Mako" alias Markas Komando,"

- Ada pula kalimat yang mengandung elemen maksud di "Aku juga tergabung di dalam Badan Permusjawaratan

Kewarganegaraan Indonesia, organisasi yang disebut-sebut berafiliasi dengan Partai Komunis Indonesia." Yang menjelaskan secara eksplisit jika Bapeko dituduh berafiliasi dengan PKI.

- Elemen ini juga ada di kalimat yang menggunakan agar sebagai penjelas. "Etalase kaca berkode $\mathrm{Z}$ itu tak pernah kubuka agar kualitas kertas tidak rusak terkena udara. Tahun ke tahun memang warnanya jadi kekuningan, bahkan kecokelatan. Tapi kumasukkan juga pengawet agar tahan lama."

\section{Elemen: Praanggapan}

Temuan:

- Praanggapan merupakan kalimat selanjutnya yang digunakan untuk menegaskan kalimat utamanya. Terdapat pada paragraf pertama, "Bukan sekadar kawan seperjuangan di pulau pengasingan, Buru. Dia seorang sastrawan, Pramoedya Ananta Toer, namanya."

- Ada pula di paragraf berikut, "Diberi kepercayaan Pak Pram menyimpan naskahnya, suatu kehormatan bagiku. Naskah

ISSN 2338 - 0861 (cetak); e-ISSN 2621 - 8712 (online)

website : http://spektrum.stikosa-aws.ac.id 
itu sudah seperti "anakku" sendiri. Aku ikut merawatnya sejak naskah-naskah itu diproduksi di Mako."

Elemen: Nominalisasi

Temuan:

- Nominalisasi ada di paragraf 28 "Selama dua tahun naskah itu kusimpan rapi setelah aku sampai di Malang, Jawa Timur, kota kelahiran yang sudah 13 tahun kutinggalkan sejak "diciduk" aparat." Juga nominalisasi terdapat di paragraf "Sampai sekarang, sudah 38 tahun naskah itu bersamaku." Dan ada pada kalimat "Pak Pram memang telah meninggal 10 tahun lalu,"

- Nominalisasi juga terdapat di paragraf "Bersama ribuan tahanan politik lain, aku dinaikkan kapal Tobelo dari Nusakambangan."

\section{Struktur Mikro (Sintaksis)}

Elemen: Bentuk kalimat

Temuan:

- Bentuk kalimat aktif yang terdapat pada paragraf dua yaitu "Pak Pram, begitu aku biasa memanggilnya, menanyakan soalan itu saat aku menemuinya di sebuah komplek tahana,"

- Selain itu, ada bentuk kalimat pasif di kalimat "Bersama ribuan tahanan politik lain, aku dinaikkan kapal Tobelo dari Nusakambangan."

Elemen: Koherensi

Temuan:

- Koherensi atau hubungan antar kata atau kalimat yang digunakan pada berita ini ditemukan di "Pak Pram sempat marah padaku. Tapi bukan karena naskahnya dirampas."

- Juga ditemukan di kalimat "Tahun ke tahun memang warnanya jadi kekuningan, bahkan kecokelatan. Tapi kumasukkan juga pengawet agar tahan lama."

- Koherensi juga terdapat di paragraf ke 32 pada kata "Pak Pram memang telah meninggal 10 tahun lalu. Tapi karyanya masih abadi, naskahnya masih tersimpan rapi, selama masih ada yang mau mengenang dan mengurusnya."

- Koherensi juga ditemukan di kalimat "Aku juga tergabung di dalam Badan Permusjawaratan Kewarganegaraan Indonesia, organisasi yang disebut-sebut berafiliasi dengan Partai Komunis Indonesia."

\section{Elemen: Kata Ganti}

Temuan: Kata ganti ditemukan dalam kalimat, "Bersama ribuan tahanan politik lain, aku dinaikkan kapal Tobelo dari Nusakambangan. "Enak enak, melok o ae [enak, enak, sudah ikut saja]," begitu iming-iming mereka kala itu." Mereka dalam kalimat ini bermaksud tentara.

\section{Struktur Mikro (Stilistik)}

Elemen: Leksikon (kosakata)

Temuan: Dalam berita terdapat unsur leksikon yang ditemui pada kata "kawan seperjuangan", "pulau pengasingan", " berafiliasi", "dipingpong", "intelektual", "tapol", "gubuk", "anakku”, "kealpaanku”, "diciduk".

\section{Struktur Mikro (Retoris)}

Elemen: Grafis

ISSN 2338 - 0861 (cetak); e-ISSN 2621 - 8712 (online)

website : http://spektrum.stikosa-aws.ac.id 
Temuan:

- Elemen grafis muncul pada kata "Mako" dalam kalimat "Pak Pram, begitu aku biasa memanggilnya, menanyakan soalan itu saat aku menemuinya di sebuah komplek tahanan yang kami juluki "Mako" alias Markas Komando.

- Ada pula beberapa kata yang diberi tanda petik sebagai penekanan grafis, seperti "diping-pong", "gubuk", "anakku".

Elemen: Metafora

Temuan:

- Dalam Metafora, terdapat paragraf yang berisi "Naskah Di Atas Lumpur yang tak pernah diterbitkan pun, ada di tanganku" maksudnya di tanganku bukan sedang dalam genggamannya namun sedang disimpan.

- Selama lima tahun sebelum dibawa ke Nusakambangan, aku terus "diping-pong" Malang-Surabaya." Kata diping-pong adalah metafora, berarti Hwie dibawa bolakbalik dari Malang ke Surabaya dan sebaliknya. Bukan dipingpong seperti permainan olahraga bola ping-pong.

Elemen: Ekspresi

Temuan:

- Ekspresi terdapat pada kalimat "Pak Pram sempat marah padaku," yang menunjukkan ekspresi kemarahan Pramoedya saat naskahnya digeledah dan mencemaskan nasib Hwie.

- "Aku deg-degan saat melewati penjagaan," yang menujukkan rasa takut dan kecemasan Hwie ketika akan digeledah.

\section{KOGNISI SOSIAL}

Pengetahuan penulis dalam memahami peristiwa di Pulau Buru ini, peneliti tulis dalam skema atau model menganalisis dari Van Dijk. Berikut Skema/ Model Kognisi Sosial Van Dijk

\section{Skema Person (Person Schemas)}

Rizky Sekar Afrisia atau Icha adalah wartawan CNNIndonesia.com yang lahir di Surabaya. Dulu, dia sempat mengawali karirnya di Tabloid Nyata, media daring viva.id, hingga kini menjadi editor atau redaktur dalam rubrik hiburan di CNNIndonesia.com. Dia mulai menulis reportase tentang naskah Pramoedya yang disimpan Hwie setelah pulang dari Pulau Buru. Icha pun menggabungkan hasil temuannya di Buru dengan apa yang dipaparkan Hwie. Sedangkan untuk penulisannya, Icha membutuhkan waktu tiga hari. Setelah melalui proses editing, berita inipun dipublikasikan pada tanggal 30 April 2016 pukul 12.22 WIB di laman CNNIndonesia.com.

\section{Skema Diri (Self Schemas)}

Kala menulis naskah berita ini, Icha masih menjadi reporter di rubrik hiburan (kini redaktur). Dia menulis ini untuk dipublikasikan di kanal fokus pada rubrik hiburan. Dia mengambil angle atau sudut pandang yang berbeda dari penulisan naskahnya yang lain yang menggunakan penulisan features deskriptif menggunakan sudut pandang orang ketiga. Sedangkan berita ini, Icha memakai sudut pandang orang pertama yakni "aku" sebagai Hwie dengan jenis penulisan features.

ISSN 2338 - 0861 (cetak); e-ISSN 2621 - 8712 (online)

website : http://spektrum.stikosa-aws.ac.id 


\section{Skema Peran (Role Schemas)}

Skema ini berkaitan dengan peran dari media naungan naskah ini berada, yakni di CNNIndonesia.com. CNNIndonesia.com sejak tahun 2014 memiliki visi misi untuk menjadi media yang independen dalam mengabarkan, juga tidak bergantung pada panjang dan pendek suatu berita. CNNIndonesia.com sebelumnya pernah mengangkat kisah Pramoedya yang ditampilkan saat memperingati ulang tahun Pram. CNNIndonesia.com memiliki peran untuk menjembatani pengetahuan wartawan akan sosok dan kisah sang maestro di bidang sastra, Pramoedya Ananta Toer kepada masyarakat umum.

\section{Skema peristiwa (Event Schemas)}

Peristiwa yang terjadi di masa pergantian Orde Lama dan Orde Baru memang berhubungan. Hal ini yang coba digambarkan Rizky Sekar Afrisia dalam tulisannya. Misalnya peristiwa G30S yang berujung ke penangkapan orang-orang yang dituduh berafiliasi dengan Partai Komunis Indonesia (PKI). Dalam beritanya, Icha juga memasukkan beberapa latar peristiwa sebagai penghidup suasana, seperti kekejaman tentara zaman Orde Baru yang menangkap tertuduh PKI tanpa proses pengadilan, menyiksa mereka, hingga membunuh.

Dalam naskah berita ini juga terdapat kisah mengenai buku-buku Pram yang tertangkap saat digeledah dan dibakar.

Pada berita 38 Tahun Menjaga Kertas Semen Titipan Pramoedya, Icha hanya mewawancarai satu narasumber utama yaitu Oei Hiem Hwie. Namun, ia juga mengaku mendapat beberapa data yang berhubungan setelah kunjungannya ke Pulau Buru, juga ke kediaman Pram untuk wawancara dengan beberapa orang terdekat Pram yang ditulis pada berita Icha yang lain. Menulis berita ini, Icha mencari referensi dari buku-buku Pramoedya, juga buku-buku yang memuat biografi sang tokoh.

\section{KONTEKS SOSIAL}

Dalam konteks peristiwa di berita 38 Tahun menjaga Kertas Semen Titipan Pramoedya ini, Indonesia waktu itu dalam keadaan reformasi dan segala macam kelamnya sejarah Orde Baru. Yang mana pada waktu itu semenjak meledaknya peristiwa G-30S, banyak terjadi kekacauan di tanah air. Kekacauan tersebut meliputi penumpasan habis PKI yang dilakukan oleh militer Indonesia.

Tak hanya itu, terjadi pula banyaknya penangkapan orang yang tertuduh sebagai antek-antek PKI. Dalam sejarahnya, di zaman reformasi, seseorang yang bergabung dengan organisasi yang berbau atau dituduh memiliki hubungan dengan PKI akan ditangkap secara paksa, begitu juga akan dipenjara tanpa memasuki proses pengadilan terlebih dahulu. Bahkan, banyak tahanan politik yang tak tahu dimana letak kesalahan mereka.

Peneliti menganalisis konteks sosial ini, terbagi ke dalam dua bagian, yaitu:

1. Praktik Kekuasaan

Konstruksi praktik kekuasaan dalam peristiwa di berita tersebut adalah antara militer Indonesia yang memiliki dominasi lebih besar terhadap tahanan politik di Pulau Buru. "Bersama ribuan tahanan politik lain, aku dinaikkan kapal Tobelo dari Nusakambangan. "Enak

ISSN 2338 - 0861 (cetak); e-ISSN 2621 - 8712 (online)

website : http://spektrum.stikosa-aws.ac.id 
enak, melok o ae [enak, enak, sudah ikut saja]," begitu iming-iming mereka kala itu. Sempat terdengar aku akan dibawa ke Pulau Buru, tapi itu hanya selentingan saja. Aku pun tak tahu ke mana aku akan dibawa. Aku ikut saja." Dari paragraf di atas, jelas sekali bagaimana praktik kekuasaan militer Indonesia terutama pada saat terjadinya masa reformasi dan Orde Baru. Ada juga paragraf yang juga menceritakan bagaimana dulu militer Indonesia memanfaatkan kekuasaannya dengan keji. Hal ini juga menggambarkan bagaimana mencekamnya suasana pada waktu itu. "Tapi malam itu berbeda. Di tengah pengetikan, Wakil Komandan Unit masuk dan merampas naskah yang ada. Termasuk Arus Balik, Mata Pusaran, dan Arok Dedes. Paimin, aku, dan Pak Pram kena damprat. Aku pun dipindah kerja dari ladang di dekat Mako, jadi lebih jauh."

2. Akses Mempengaruhi Wacana

Dalam akses mempengaruhi wacana, tentu saja militer Indonesia mempunyai kekuatan yang dominan. Dari macam-macam akses yang Van Dijk kemukakan, militer Indonesia memilki akses yang disebut dengan akses perencanaan (planning), akses wacana dalam hal setting, akses wacana dalam hal mengontrol peristiwa komunikasi (communicative event), dan kontrol wacana atas khalayak.

Hal ini dapat dilihat dari pemaparan peristiwa dalam berita "38 Tahun Menjaga Kertas Semen Titipan Pramoedya." Pertama, peristiwa ketika Hwie pertama dibawa ke Pulau Buru dengan ribuan orang menggunakan kapal. Dalam peristiwa tersebut terlihat militer sangat dominan, hal inilah yang membuat Hwie menurut saja ketika diangkut dengan kapal dan entah akan dibawa kemana.

Ada pula paragraf yang berisi "Nasibku masih beruntung, tak terlalu banyak dipukul. Wartawan dan mahasiswa yang dianggap kalangan intelektual, memang tidak terlalu disiksa. Yang jelas-jelas anggota PKI, siksaannya tiada ampun. Dipukul, bahkan dibunuh." Hal ini yang juga menyebabkan wacana yang berkembang kepada masyarakat jika militer Indonesia pada jaman Orde Baru memiliki jejak yang buruk.

\section{KESIMPULAN}

Dalam tatanan teks, berita ini cukup mampu memaparkan kisah Hwie yang menjaga naskah asli Pramoedya. Dari sisi semantik, yakni penekanan makna, yang dilakukan wartawan cukup baik. Terlebih pada segi latar mampu membawa pembaca memasuki suasana masa lampau saat kelamnya masa Orde Baru.

$$
\text { Untuk elemen leksikon, }
$$
pemilihan kosakata cukup merepresentasikan suasana kala itu, seperti kata "pulau pengasingan" hingga "diciduk" yang memiliki makna negatif pada militer Indonesia. Berita ini bergenre features yang kaya data, memiliki deskripsi dan detail yang baik sehingga pembaca tidak hanya mengerti kisah Hwie, namun juga pengetahuan sejarah yang terjadi selama masa Orde Baru.

Dari sisi kognisi sosial, Rizky Sekar Afrisia, penulis berita ini adalah penggemar Pramoedya Ananta Toer. Berita mengenai Hwie awalnya tidak masuk dalam perencanaan peliputan seperti di Pulau Buru. Pengetahuan pribadinya sebagai orang Surabaya akhirnya membawanya pergi ke perpustakaan Hwie di Surabaya. Dalam penulisan, Rizky Sekar Afrisia yang biasa dipanggil Icha lebih suka

ISSN 2338 - 0861 (cetak); e-ISSN 2621 - 8712 (online)

website : http://spektrum.stikosa-aws.ac.id 
menulis features menggunakan banyak deskripsi, juga membuat pembaca masuk ke jalinan cerita. Hal ini yang membuatnya menulis kisah Hwie dengan sudut pandang "aku" karena ingin naskah ini berbeda dengan naskah lainnya.

Sedangkan konteks sosial dilihat dari kondisi Indonesia di masa kekuasaan Soeharto di zaman Orde Baru yang digambarkan powerful. Terlihat dari ketika ada yang menghalangi kekuasaannya, akan ditumpas habis, entah dipenjara tanpa melalui proses persidangan atau bahkan dibunuh. Meski dalam tulisannya, Icha hanya ingin menceritakan kisah Pram dan Hwie semasa menjadi tapol di Pulau Buru, secara tidak langsung, latar sejarah yang terjadi turut menjadi bumbu dalam berita.

\section{DAFTAR PUSTAKA}

Aris Badara. Analisis Wacana : Teori, Metode, dan Penerapannya pada Wacana Media. 2010

Eriyanto. "Analisis Wacana, pengantar analisis teks media". Yogyakarta: LkiS. 2001.

Hikmat dan Purnama Kusumaningrat. "Jurnalistik Teori dan Praktik". Bandung: Remaja Rosdakarya. 2014.

Harsono, Andreas dan Budi Setiyono, ed. 2005. Jurnalisme Sastrawi : Antologi Liputan Mendalam dan Memikat. Jakarta: KPG-Pantau.

Kovach, Bill dan Tom Rosenstiel. Sembilan Elemen Jurnalisme. Jakarta: Yayasan Pantau. 2006.

Kriyantono, Rachmat. "Teknik Praktis Riset Komunikasi". Jakarta: Kencana Prenada Media Group. 2009.

Mursito BM. "Memahami Institusi Media", Surakarta: Lindu Pustaka \& SPIKOM. 2006.
Rakhmat, Jalaluddin. "Metode Penelitian Komunikasi". Bandung: Remaja Rosdakarya. 2003.

Romli, Asep Syamsul M. Jurnalistik Online. Bandung: Baticpress. 2005.

Santana, Septiawan. "Jurnalisme Kontemporer". Jakarta: Yayasan Obor Indonesia. 2005.

Sobur, Alex. "Analisis Teks Media". Bandung: Remaja Rosda Karya. 2001.

Sumadiria, AS Haris. Jurnalistik Indonesia, Menulis Berita dan Feature, Panduan Praktis Jurnalis Profesional. Bandung: Simbiosa Rekatama Media. 2005.

Website :

www.kominfo.go.id diakses pada 19 Maret 2017

www.pantau.or.id diakses pada 28 Desember 2017

www.cnnindonesia.com

ISSN 2338 - 0861 (cetak); e-ISSN 2621 - 8712 (online) website : http://spektrum.stikosa-aws.ac.id 